\title{
MECANISMOS EPIGENÉTICOS NO CÂNCER DE MAMA: O PAPEL DOS BIOMARCADORES E DA MEDICINA PERSONALIZADA
}

\author{
EPIGENETIC MECHANISMS IN BREAST CANCER: THE ROLE OF BIOMARKERS AND \\ PERSONALIZED MEDICINE
}

\section{RESUMO}

A epigenômica é uma área em ampla discussão atualmente. Estuda-se como fatores externos podem promover alterações genéticas com potencial hereditário e a patogenicidade dessas mudanças. O objetivo deste trabalho é identificar o papel dos genes supressores de tumor enquanto biomarcadores do câncer de mama e relacionar mecanismos epigenéticos do câncer de mama com estratégias de medicina de precisão. Trata-se de uma revisão de literatura do período entre 2010 e 2018, de artigos indexados na base de dados MEDLINE e de teses e dissertações disponíveis no portal Periódicos CAPES, além de materiais informativos do Ministério da Saúde, do Instituto Nacional do Câncer e da Organização Mundial da Saúde. Os genes BRCA1 e BRCA2 desenvolvem um papel crucial na supressão de tumores mamários por meio da reparação do DNA. Alterações epigenéticas que levam ao silenciamento deles indicam instabilidade genômica e sugerem que alternativas de reparação são buscadas e podem favorecer a carcinogênese. Avaliações moleculares já permitiram identificar que determinadas alterações especialmente no padrão de metilação - se expressam em diferentes pacientes e seus prognósticos. A abordagem personalizada utiliza destas informações para avaliar e tratar os pacientes de forma mais efetiva. No entanto, entende-se que tais estudos são preliminares. Novos estudos são necessários para atestar a segurança e aplicabilidade dessas ferramentas.

Palavras-chave: Câncer de Mama. Epigenômica. Medicina de Precisão.

\footnotetext{
1 Especialista em Língua Portuguesa e Literatura Brasileiras pela Universidade Cândido Mendes, licenciado em Letras pela Universidade Estácio de Sá, graduando em Medicina pelo Centro Universitário Tiradentes (UNIT). E-mail: arthur_rodrigues@live.com 2 Graduanda em Medicina pelo Centro Universitário Tiradentes (UNIT). E-mail: carol250100@hotmail.com 3 Graduanda em Medicina pelo Centro Universitário Tiradentes (UNIT). E-mail: cduartecavalcante@gmail.com

4 Graduada em Farmácia pela Universidade Federal de Alagoas (UFAL), graduanda em Medicina pelo Centro Universitário Tiradentes (UNIT).E-mail: amanda.peixoto_@hotmail.com
} 


\section{ABSTRACT}

Epigenomics is an area of wide discussion today. It is studied how external factors can promote genetic changes with hereditary potential and the pathogenicity of these changes. The aim of this paper is to identify the role of tumor suppressor genes as breast cancer biomarkers and to relate epigenetic mechanisms of breast cancer with precision medicine strategies. This is a literature review from 2010 to 2018, articles indexed in the MEDLINE database and theses and dissertations available on the Periódicos CAPES portal, as well as informative materials from the brazilian Ministry of Health, the National Cancer Institute in Brazil and World Health Organization. The BRCA1 and BRCA2 genes play a crucial role in suppressing breast tumors through DNA repair. Epigenetic changes that lead to their silencing indicate genomic instability and suggest that repair alternatives are sought and may favor carcinogenesis. Molecular evaluations have already allowed us to identify that certain changes especially in the methylation pattern - are expressed in different patients and their prognoses. The personalized approach uses this information to evaluate and treat patients more effectively. However, it is understood that such studies are preliminary. Further studies are needed to attest to the safety and applicability of these tools.

Keywords: Breast Cancer. Epigenomics. Precision Medicine.

\section{INTRODUÇÃO}

A alteração no estilo de vida populacional, em pauta a adoção de hábitos de vida não saudáveis, é relevante no avanço dos problemas de saúde pública tanto para os países desenvolvidos quanto para os em desenvolvimento. O câncer é uma doença multifatorial que engloba alterações tanto genéticas quanto epigenéticas, sendo responsável por mais de $12 \%$ de todas as causas de óbito no mundo (INCA, 2017).

Dentre todos os tipos de neoplasias malignas, o câncer de mama (CM) é o que se destaca no sexo feminino, visto que, conforme a Agência Internacional para a Pesquisa do Câncer, esse é o tipo mais incidente e de maior taxa de mortalidade em mulheres no mundo (IARC, 2012).

É por esse motivo que o controle dele é atualmente uma prioridade da agenda de saúde no Brasil e integra o plano de ações estratégicas para o enfrentamento das Doenças Crônicas Não Transmissíveis - DCNT (MALTA; SILVA JR, 2014). Segundo o Ministério da Saúde (BRASIL, 2013), existem fatores de risco associados ao câncer de mama, especialmente aqueles relacionados à vida reprodutiva da mulher (menarca precoce, nuliparidade, primeira gestação antes dos 30 anos, uso de anticoncepcionais orais, menopausa tardia e terapia de reposição hormonal). No entanto, a idade é um dos fatores mais importantes. 
(MIGOWSKI et al., 2018) Mulheres mais velhas, sobretudo a partir dos 50 anos, são mais propensas a desenvolver a doença. O Instituto Nacional do Câncer - INCA estimou que 59.700 novos casos seriam identificados em 2018 (INCA, 2017).

A datar do ano 1865, quando Gregor Mendel anunciou as leis da hereditariedade, os genes têm sido considerados como a única forma de transmissibilidade dos caracteres hereditários. Todavia, existem evidências de que as variações não genéticas podem ser transmitidas para os descendentes. Nesse contexto, a epigenética manifesta-se como uma ciência que estuda os mecanismos de alterações químicas que atuam na regulação e modificação do perfil da expressão gênica - modificações do DNA e das histonas que são herdáveis e não alteram a sequência de bases do DNA. As principais alterações epigenéticas são: metilação do DNA, modificações pós-traducionais das histonas e os RNA não-codificadores, sendo a metilação no DNA o processo epigenético mais bem detalhado e estudado em eucariontes. Através desses, conclui-se que o epigenoma é dinâmico e varia de célula para célula dentro de um mesmo organismo multicelular, o que pode explicar o desenvolvimento de patologias, como o câncer de mama (BYLER et al., 2014).

Cada organismo apresenta um quadro único frente ao câncer de mama, o que sugere que a abordagem de cada caso seja estruturada individualmente. Portanto, exames genéticos e moleculares podem ser ferramentas úteis na definição prévia da probabilidade de desenvolvimento da doença e assim, elaborar a melhor conduta a partir dos resultados, de modo a viabilizar o monitoramento do desenvolvimento, progressão, resposta terapêutica e recorrência do carcinoma, sendo a medicina personalizada o modelo médico que realiza tais procedimentos. Esse padrão de singularidade é oferecido aos pacientes após a coleta de informação genômica e relacionada a moléculas de RNA, proteínas e vários metabólitos. A interpretação de tais dados é crucial na identificação de fatores de predisposição a determinadas condições (NAGINI, 2017).

A Política Nacional de Atenção Integral às Pessoas com Doenças Raras prevê atenção em genética clínica apenas para anomalias congênitas ou de manifestação tardia, deficiência intelectual e erros inatos do metabolismo (BRASIL, 2014). O mapeamento genético ainda não é acessível à população por ter um custo elevado, mesmo sendo cobertura obrigatória pelos planos de saúde, de acordo com a Agência Nacional de Saúde Suplementar (ANS).

\section{OBJETIVOS}

Identificar o papel dos genes supressores de tumor enquanto biomarcadores no diagnóstico do câncer de mama; Descrever a relação entre a epigenética e o câncer de mama no desenvolvimento de estratégias personalizadas na prática clínica. 


\section{METODOLOGIA}

Para a elaboração desta revisão integrativa, foram estabelecidas as hipóteses e objetivos do trabalho, os critérios de inclusão e exclusão de artigos, teses ou dissertações, definição das informações que seriam extraídas dos textos selecionados; análise e discussão dos resultados de acordo com a temática proposta; e a integralização destes textos.

Para a seleção dos textos, foram utilizadas as bases de dados MEDLINE, bem como teses e dissertações encontradas no portal de periódicos da Coordenação de Aperfeiçoamento de Pessoal de Nível Superior - CAPES. Também foram utilizados materiais do Ministério da Saúde brasileiro, da Food and Drug Administration - FDA e dados estatísticos do Instituto Nacional do Câncer - INCA e da Organização Mundial da Saúde - OMS.

As palavras-chave utilizadas na obtenção do material foram "Neoplasias da Mama", "Epigenômica" e "Medicina de Precisão" e seus termos correspondentes em língua inglesa, todos descritores indexados no DeCS e no MeSH, combinados com a utilização dos operadores booleanos "AND" e "OR".

Os critérios de inclusão dos artigos definidos para esta revisão foram: artigos, teses ou dissertações publicados em língua portuguesa, inglesa ou espanhola, com resumos disponíveis nas bases de dados selecionadas, no período compreendido entre 2010 e 2018.

Além disso, foram considerados os estudos cuja abordagem era voltada ao processo de metilação no câncer de mama e a utilização dos biomarcadores BRCA 1 e BRCA 2 na identificação de predisposições à carcinogênese e também no diagnóstico e tratamento da referida doença com enfoque o individual e personalizado característico da medicina de precisão.

Foram excluídos os artigos de revisão bibliográfica e aqueles com enfoque nos demais mecanismos epigenéticos, pois a literatura acerca deles ainda é bastante escassa e ainda não possui aplicabilidade clínica. Após este processo, foram mantidos 28 trabalhos.

\section{RESULTADOS}

\subsection{CARCINOGÊNESE E O CÂNCER DE MAMA}

A carcinogênese, também denominada oncogênese, é o processo pelo qual células normais se transformam em células cancerígenas-formação do câncer. Este, é um processo cumulativo e microevolutivo onde há a perda do comando do ciclo celular, o que resulta na capacidade de proliferação descontrolada, fenótipo invasivo e, diversas vezes, na resistência a uma grande variedade de fármacos citotóxicos. Responsáveis pela progressão e promoção do câncer, as mutações de 
DNA envolvendo oncogenes (OG) e genes supressores de tumor (ETG) compõem alterações genéticas do desenvolvimento do câncer. Entretanto, dados recentes sugerem uma co-ocorrência entre mecanismos genéticos e epigenéticos, estes que envolvem processos de metilação do DNA, modificações histônicas e desregulações do MiRNA, estando esses dois tipos de estabilidade estreitamente relacionadas (PERRI et al., 2017).

O câncer de mama (CM) é o segundo tipo de câncer mais frequente no mundo e o mais comum entre as mulheres. Por isso, é provavelmente o mais temido pela população feminina, uma vez que, além de sua alta frequência, os efeitos psicológicos decorrentes da percepção de sexualidade e imagem pessoal são evidentes. No Brasil, a cada ano, cerca de $20 \%$ dos casos novos de câncer em mulheres são de mama (INCA, 2008). Este, possui etiologia complexa, uma vez que está associada a extensas alterações no microambiente circular, nos níveis moleculares, genômicos e metabólicos (STEWART et al., 2018).

Dentre os fatores de influencia externa, as terapias de reposição hormonal - hormônios usados para combater os sintomas da menopausa - destacam-se, uma vez que o estrógeno induz o crescimento das células do tecido mamário, o que aumenta o potencial de alterações genéticas e, consequentemente, o desenvolvimento do câncer de mama (INCA, 2008). Além disso, o sedentarismo e a obesidade são fatores intimamente relacionado à neoplasia maligna mamária, tendo em vista que o primeiro, assim como o segundo, pode desencadear aumento do tecido adiposo e, consequentemente uma maior secreção de estrógenos, visto que este funciona como reservatório de esteróides. Além dessas condições, aqueles que se encontram relacionados à vida reprodutiva da mulher (menarca precoce, antes dos 11 anos, nuliparidade, primeira gestação acima de 30 anos, uso de contraceptivos orais, menopausa tardia e utilização de reposição hormonal) estão bem estabelecidos (INCA, 2007).

\subsection{A EPIGENÉTICA DO CÂNCER}

O conceito de plasticidade genômica define a habilidade de um dado genótipo conferir várias manifestações - fenótipos - na presença de diferentes fatores. Os mecanismos epigenéticos controlam as modificações nessas expressões genéticas. Nesse contexto, a epigenética refere-se a mudanças hereditárias na expressão gênica que ocorrem sem alterar a sequência de DNA. Ela fornece informações sobre o efeito da organização da cromatina na regulação da transcrição. Existem três principais modificações epigenéticas: A metilação do DNA - melhor conhecida e, portanto, mais amplamente aplicada na prática clínica - e também por modificações nas histonas e silenciamento gênico mediado por RNA interferente. (DEANS e MAGGERT, 2015) Essas modificações no DNA são feitas e desfeitas constantemente, exceto nos casos de marcadores constitutivos, 
que são herdados geneticamente, já que os indivíduos têm contato com agentes promotores durante toda a vida. Desta forma, alterações epigenéticas podem ser suscitadas no genoma em algum momento da vida e elas, por sua vez, podem ser de ordem patológica.

A metilação do DNA envolve a adição de grupo metila ao quinto carbono da citosina - base nitrogenada presente no DNA. Esse processo é crucial para o desenvolvimento normal da célula, sua proliferação e manutenção da estabilidade gênica. Ela ocorre principalmente em dinucleotídeos CpG em células diferenciadas e desempenham função essencial na regulação da expressão gênica e no silenciamento de elementos repetidos no genoma. A metilação é usualmente associada a repressão da cromatina e a inibição da expressão dos genes. Tal processo ocorre através do bloqueio da ligação de fatores de transcrição ao DNA. Ainda, "proteínas MBPs com afinidade pelo grupo metil, ligam-se as regiões CpGs localizadas nos promotores e impedem o acesso dos fatores de transcrição aos seus sítios" (MELO, 2015).

O processo de metilação é promovido por enzimas metiltransferases DNMT1, DNMT1B, DNMT1O, DNMT2, DNMT3a, DNMT3b, DNMT3I. Dessas, só se conhece a atividade catalítica de três: DNMT1, DNMT3a e DNMT3b. No geral, elas podem ser divididas em dois grupos: O das envolvidas na metilação de fitas hemimetiladas do DNA - metilases de manutenção e o grupo, que é responsável pela maioria dos processos de metilação de novo, que ocorrem em sítios sem indicação de metilação. Essas enzimas precisam de um substrato que funcione como doador do radical metil. Normalmente, esses são obtidos da dieta. Um outro grupo é responsável pela desmetilação do DNA - desmetilases - necessárias para ativar genes específicos ou apagar marcas epigenéticas durante o desenvolvimento ou em respostas às perturbações ambientais. (MIRZA et al., 2013)

Alterações no processo de metilação tem um importante papel no desenvolvimento do câncer de mama, bem como de outras doenças como a síndrome de Rett, imunodeficiência e síndrome de Prader-Willi. Felicio (2015) distinguiu essas modificações epigenéticas em duas categorias: A hipometilação genômica pode causar instabilidade genômica e aneuploidia, perda de imprinting genômico e mudanças de expressão genética metilados anteriormente - e a hipermetilação (metilação aberrante), que é responsável pelo silenciamento dos genes supressores de tumores.

As modificações de histonas têm ganhado uma maior importância no contexto da epigenética. Elas podem sofrer metilação, acetilação, fosforilação e ubiquitinação. Essas modificações desestabilizam as interações entre histonas e DNA de modo a influenciar o processo de transcrição gênica e, portanto, essas transformações, no contexto da patologia cancerígena, também podem ser associadas a malignidade e a metástase (WU, SARKISSYAN e VADGAMA, 2015). 
MicroRNA são sequências mais curtas de RNA capazes de ligar-se ao RNA mensageiro alvo, encaminhando-os para o silenciamento de genes pós-transcritos ou para a degradação. Dessa forma, eles exercem controle epigenético sobre o ciclo celular, apoptose e outros processos essenciais para a homeostase (PERRI et al., 2017). Ou seja, a regulação epigenética é responsável por diferentes respostas quando a mesma sequência de DNA sofre influência de diferentes fatores. No contexto do câncer, a avaliação do perfil de metilação já é considerada um potencial marcador molecular de vários tipos de tumor. Em tumores esporádicos de neoplasias mamárias, por exemplo, é observada a hipermetilação dos genes supressores tumorais BRCA1, BRCA2, CDKN2A (pl6), GSTP1, CDH1 e RASSF1. (NEBBIOSO ET AL., 2018).

\subsection{AVALIAÇÃO MOLECULAR}

Devido a heterogeneidade tumoral do microambiente celular, o desenvolvimento de biomarcadores nas últimas décadas foi fulcral a uma melhor compreensão no que tange aos mecanismos celulares e moleculares sobre o crescimento e evolução do tumor. Em virtude dos avanços nesta área, novas opções terapêuticas e estratégias de tratamento foram desenvolvidas e conduzem um progresso diante dos carcinomas. Outrossim, conforme Kalia (2015), outro ponto relevante são os diagnósticos preditivos, posto que estes predizem a ocorrência patológica antes mesmo da instalação desta nos tecidos. Nessa perspectiva, técnicas de sequenciamento, citogenética e microarrays em portadoras de CM e em seus familiares difundiu na sociedade o que conhecemos como medicina personalizada.

Supressores tumorais são genes que reduzem a probabilidade de uma célula em um organismo multicelular de se tornar um tumor, uma vez que possuem o papel de codificar proteínas essenciais à regulação do ciclo celular, apoptose e reparação do DNA. Sendo assim, alterações como o silenciamento da expressão desses genes aumentam consideravelmente o risco de desenvolvimento dessas neoplasias malignas (PASCULLI, BARBANO E PARRELLA, 2018). Os genes BCRAl e BCRA2 são os mais destacados no CM e possuem a função de impedir a formação de tumores por meio da reparação de moléculas de DNA. Sob essa égide, desempenham um papel crítico na manutenção da estabilidade de informação genética de uma célula (LYNCH; SNYDER; CASEY, 2013). Diante de mutações decorrentes de agressões ao DNA - defeitos no processo de replicação, exposição a radiação solar, às toxinas no ar ou alimentos, consumo de drogas, etc., - esses genes podem perder sua capacidade protetora, predispondo o aparecimento de tumores malignos.

Localizado no cromossomo 17 (17q21), o BRCA1 foi dado como primeiro gene de susceptibilidade ao câncer de mama. Este, expressa uma proteína pleiotrópica 
que atua ativando o checkpoint na célula e no repara ao DNA. Mais tarde, foi identificado outro gene, o BRCA2, que age no mecanismo de recombinação homóloga. (RAMALHO, 2012).

Aponta-se que, a transcrição desses dois genes - BRCA1 e BRCA2 - resulta em proteínas que possuem a capacidade de atuar em uma via de proteção ao genoma, diante da reparação e resposta aos danos no DNA (PARRELLA, 2018). Sendo assim, uma vez silenciados, há um indicativo de instabilidade genômica: translocações, duplicações e fusões aberrantes entre cromossomos não-homólogos, vias alternativas de reparação encontradas pelas células. E, esta instabilidade é crucial ao desenvolvimento da carcinogênese (LALLOO e EVANS, 2012).

As anormalidade epigenéticas são possíveis de ocorrer em todos os estágios da gênese do tumor. Dentre essas anormalidades, destacam-se no desenvolvimento tumoral a anomalia na metilação e mudanças nas histonas das cromatinas. A metilação do DNA ocorre nos sítios CpG e não CpG, estando assim interligadas à regulação gênica. Esta modificação não-genética, que pode ser herdada, é responsável pela manifestação de mecanismos de inibição de genes, incluindo os supressores de tumor (MUGGERUD,2010).

Em aproximadamente $20 \%$ dos tumores esporádicos, têm-se observado a ocorrência de metilação aberrante nos promotores gênicos - hipermetilação. Esta, coaduna com a baixa ou ausência da expressão dos genes em questão (RAMALHO, 2012). Esses tumores apresentam negatividade para receptores de progesterona, estrógeno e HER-2, os quais apresentam características patológicas semelhantes aos tumores de etiologia familiar onde foram detectadas mutações germinativas no gene BRCAl (GYÖRFFY et al., 2016). Além disso, há associação do nível de metilação ao estadiamento clínico, grau histológico, fenótipo triplo-negativo e ancestralidade, embora há poucas evidências sobre o perfil de metilação e o CM hereditário. (LOW; ZEMBUTSU; NAKAMURA, 2018).

Paralelo a pacientes cujo gene BRCAl não encontra-se metilado, os portadores da metilação nesse gene apresentam redução tanto a sobrevida total como na livre da doença. Além disso, é sugestivo que, o grau de metilação do gene BRCAl é um aspecto prognóstico superior ao tamanho tumoral, metástase linfonodal, grau histológico e idade nos casos de CM com diagnóstico em idade jovem (COSTA-PINHEIRO et al., 2015).

Desse modo, os avanços na pesquisa por testes moleculares tumorais são altamente explorados na atualidade com o objetivo de minimizar tratamentos agressivos e contribuir para a detecção precoce do CM. Sendo assim, esses testes têm permitido avanços sobre o prognóstico tumoral, recidivas e outras variáveis do fenótipo tumoral.

Apesar de haverem hipóteses, não se sabe ao certo de que modo o mecanismo epigenético de metilação da região promotora do DNA atua no silenciamento gênico, entretanto, em linhas gerais, a aquisição dessas alterações 
genéticas - mutações, polimorfismos - ou epigenéticas - hipermetilação da região promotora do gene - em genes reguladores do ciclo celular, responsáveis pela apoptose, ou genes de reparo do DNA é fundamental para que a célula torne-se autônoma e desenvolva-se livremente (KATSIOS, 2010).

\subsection{O PAPEL DA MEDICINA PERSONALIZADA: DIAGNÓSTICO E TERAPÊUTICA}

O desenvolvimento da ciência epigenômica fornece interfaces de atenção personalizada e cada vez mais precisa para diversas patologias, inclusive o câncer. A caracterização individual do genoma permite o estudo de elementos genéticos e epigenéticos concernentes a probabilidade de desenvolver patologias, determinar subtipos e manifestações atípicas delas e direcionar o desenvolvimento de estratégias terapêuticas adaptadas às expectativas de resposta de cada indivíduo tratado. Tannock e Hickman (2016) acreditam que aprender mais sobre características da variabilidade molecular dos tumores de cada indivíduo e a relação com a história natural da doença é importante, mas atualmente não facilita a escolha de tratamento.

A FDA - Food and Drug Administration (2013) considera que o crescente aumento da busca pela medicina personalizada se dá pelo notável avanço de áreas como a farmacogenômica - ciência que faz uso de estudos de variações genéticas e epigenéticas apenas relacionadas a resposta a drogas - além de avanços nas tecnologias terapêuticas que levam em consideração fatores genéticos, anatômicos e fisiológicos. Claramente, deve haver critério e pleno entendimento por parte dos serviços de saúde e pacientes de que a medicina personalizada é um campo relativamente novo, em ampla ascensão, mas com expressivas limitações.

Russell (2014) afirma que nem todos os pacientes são igualmente beneficiados pela terapia endócrina, quimioterapia ou terapias de alvo. Por conta disso, muito se espera que esse melhor conhecimento das características genéticas dos indivíduos seja aplicado de forma mais ampla na prática clínica, para que novos alvos sejam traçados de acordo com as mutações específicas que levaram ao surgimento e crescimento de células tumorais, bem como as metástases.

O desenvolvimento do conhecimento relativo a medicina personalizada e de precisão, bem como das tecnologias empregadas nesse campo têm mostrado um imenso potencial de eficiência. Qu, X. et al. (2017), por exemplo, testou o uso de nanomateriais na identificação e expedição de medicamentos em diminutos aglomerados de células neoplásicas mamárias em ratos e encontrou resultados promissores. O estudo desse tipo de intervenção ainda é bem inovador e, portanto, experimental, já que a maioria das abordagens relacionadas ao material genético e as alterações epigenéticas ainda são bem primárias e dizem respeito ao 
rastreamento de biomarcadores e mapeamento genético em busca de alterações na sequência de DNA. Estas últimas já são mais comuns, mas por conta do alto custo e da especificidade da indicação médica, ainda não fazem parte da rotina clínica. No entanto, o desenvolvimento deste campo já se mostra fundamental também na redução de complicações causadas pelo tratamento do câncer de mama. Um estudo conduzido por MESQUITA (2010, apud GUSMÃO, 2017, p.155) demonstrou que as principais complicações após a mastectomia - procedimento cirúrgico mais utilizado no tratamento de CM - são as dores em membros superiores e as limitações e bloqueios da amplitude de movimento articular, perda de força no cíngulo do membro superior, lesões nervosas e problemas relacionados a cicatrização.

A adoção da medicina de precisão personalizada nos serviços públicos de saúde depende do andamento de novos estudos ainda mais rigorosos e podem demandar um grande investimento das esferas governamentais. No entanto, a longo prazo, os benefícios desse novo viés - Melhora geral de saúde, redução do número de internações, procedimento, recorrência de patologias - superam o investimento e podem, inclusive, reduzir custos relativos a tratamento de doenças que poderiam ser prevenidas e a sobrecarga dos sistemas de saúde (KAYE et al., 2012).

\section{CONCLUSÃO}

O estudo da ciência epigenômica está em ascensão tanto pela identificação de padrões de fenótipo, quanto pela possibilidade de aliar os dados desses padrões individuais a prevenção, diagnóstico e tratamento de diversas patologias, incluindo o câncer de mama. A identificação de alterações em genes supressores de tumor tem um enorme potencial para se tornar uma ferramenta valiosa na identificação precoce e no tratamento da doença e essa abordagem personalizada, que utiliza dados colhidos a partir de mapeamentos genéticos e análise molecular, favorece aspectos como segurança e eficácia. No entanto, esses trabalhos ainda são preliminares e a análise genética ainda não é tão acessível.

Portanto, novos estudos são necessários para que haja plena adoção desses parâmetros, tanto pela necessidade de conhecer melhor o poder de influência das alterações epigenéticas, quanto para interpretar essas informações sob a ótica da medicina de precisão.

\section{REFERÊNCIAS}

BRASIL. Ministério da Saúde. Secretaria de Atenção à Saúde. Departamento de Atenção Básica. Controle dos cânceres do colo do útero e da mama / Ministério da Saúde, Secretaria de Atenção à Saúde, Departamento de Atenção Básica. - 2. ed. - Brasília : Editora do Ministério da Saúde, 2013. 
BRASIL. Ministério da Saúde. Portaria n 199, de 30 de janeiro de 2014. Política Nacional de Atenção Integral às Pessoas com Doenças Raras, 2014.

BYLER, S. et al. Genetic and Epigenetic Aspects of Breast Cancer Progression and Therapy. Anticancer Research, v. 34, n. 3, p. 1071-1077, 1 mar. 2014.

COSTA-PINHEIRO, P. et al. Diagnostic and prognostic epigenetic biomarkers in cancer. Epigenomics, v. 7, n. 6, p. 1003-1015, 1 set. 2015.

DEANS, C.; MAGGERT, K. A. What do you mean, "Epigenetic"? Genetics, v. 199, n. 4, p. 887-896, 2015.

FELICIO, P. S. Caracterização Genética e Epigenética do Gene BRCA1 em Mulheres Brasileiras em Risco Para Câncer de Mama Hereditário. Barretos. 2015. Dissertação (Mestrado em Ciências da Saúde) - Fundação PIO XII - Hospital de Câncer de Barretos, São Paulo.

GUSMÃO, Mayra Ferraz Santos et al. Encaminhamento De Mulheres Mastectomizadas Ao Serviço De Fisioterapia. InterScientia, v.5, n.1, p.147-157, Paraíba, 2017.

GYŐRFFY, B. et al. Aberrant DNA methylation impacts gene expression and prognosis in breast cancer subtypes. International Journal of Cancer, v. 138, n. 1, p. 87-97, 1 jan. 2016.

IARC. Estimated number of deaths, females, worldwide (top ten cancer sites) in 2012. International Agency for Research on Cancer - WHO, 2012. Disponível em: $<$ http://gco.iarc.fr/today/online-analysis-multi-bars?mode=cancer\&mode_population $=$ who \&population $=900 \&$ sex $=2 \&$ cancer $=29 \&$ type $=1$ \&statistic $=0 \&$ prevalence $=0 \&$ color_palette=default> Acesso em: 14 abr. 2018.

INCA. Estimativas 2018: Incidência de Câncer no Brasil. Rio de Janeiro: INCA, 2017 Disponível em: <http://www.inca.gov.br/conteudo_view.asp?id=1793> Acesso em: 14 abr. 2018.

KALIA, M. Biomarkers for personalized oncology: Recent advances and future challenges. Metabolism: Clinical and Experimental, v. 64, n. 3, p. S16-S21, 2015.

KATSIOS, C.; ROUKOS, D. H. Individual genomes and personalized medicine: life diversity and complexity. Personalized Medicine, v. 7, n. 4, p. 347-350, 2010.

KAYE, J. et al. From patients to partners: participant-centric intiatives in biomedical research. Nature Review Genetics, v. 13, n. 5, p. 371-376, 2013.

LALLOO, F.; EVANS, D. G. Familial Breast Cancer. Clinical Genetics, v. 82, n. 2, p. 105114, 1 ago. 2012. 
LOW, S.-K.; ZEMBUTSU, H.; NAKAMURA, Y. Breast cancer: The translation of big genomic data to cancer precision medicine. Cancer science, v. 109, n. 3, p. 497-506, mar. 2018

LYNCH, H. T.; SNYDER, C.; CASEY, M. J. Hereditary ovarian and breast cancer: What have we learned. Annals of Oncology, v. 24, n. SUPPL.B, 2013.

MALTA, Deborah Carvalho; SILVA JR., Jarbas Barbosa da. Plano de Ações Estratégicas para o Enfrentamento das Doenças Crônicas Não Transmissíveis no Brasil após três anos de implantação, 2011-2013. Epidemiol. Serv. Saúde, Brasília, v. 23, n. 3, p. 389395, Sept. 2014

MELO, A. R. D. S. Influência Da Exposição Solar No Perfil De Metilação De Dna Dos Genes Mmp9 E Mir137. João Pessoa. 2015. Dissertação (Mestrado em Biologia Celular e Molecular) - Universidade Federal da Paraíba, Paraíba.

MIGOWSKI, Arn et al . Diretrizes para detecção precoce do câncer de mama no Brasil. II - Novas recomendações nacionais, principais evidências e controvérsias. Cad. Saúde Pública, Rio de Janeiro, v. 34, n. 6, e00074817, 2018.

MIRZA, S. et al. Expression of DNA methyltransferases in breast cancer patients and to analyze the effect of natural compounds on DNA methyltransferases and associated proteins. Journal of Breast Cancer, v. 16, n. 1, p. 23-31, 2013.

MUGGERUD, A. A. et al. Frequent aberrant DNA methylation of $A B C B 1, F O X C 1$, PPP2R2B and PTEN in ductal carcinoma in situ and early invasive breast cancer. Breast cancer research : BCR, v. 12, n. 1, P. R3-R3, 2010.

NAGINI, S. Breast Cancer: Current Molecular Therapeutic Targets and New PlayersAntiCancer Agents in Medicinal Chemistry, 2017.

NEBBIOSO, A. et al. Cancer epigenetics: Moving forward. PLoS genetics, v. 14, n. 6, p. e1007362-e1007362, 7 jun. 2018.

PARRELLA, P. The value of epigenetic biomarkers in breast cancer. Biomarkers in Medicine, v. 12, n. 9, p. 937-940, 25 jul. 2018.

PASCULLI, B.; BARBANO, R.; PARRELLA, P. Epigenetics of breast cancer: Biology and clinical implication in the era of precision medicine. Seminars in Cancer Biology, $\mathrm{V}$. 51, p. $22-35,2018$

PERRI, F. et al. Epigenetic control of gene expression: Potential implications for cancer treatment. Critical Reviews in Oncology/Hematology, v. 111, p. 166-172, 2017. 
QU, X. et al. Guiding nanomaterials to tumors for breast cancer precision medicine: from tumor-targeting small-molecule discovery to targeted nanodrug delivery. Npg Asia Materials, v. 9, p. e452, 8 dez. 2017.

RAMALHO, Eduardo Augusto Vasconcelos de Freitas. Avaliação de alterações nos genes p53, BRCA1 e BRCA2 em carcinoma ductal invasivo (CDI) de mama humana. Recife, 2012. 46f. Dissertação (mestrado) - Universidade Federal de Pernambuco. CCB. Biologia Aplicada à Saúde, 2012

RUSSELL, C. A. Personalized medicine for breast cancer: It is a new day! American Journal of Surgery, v. 207, n. 3, p. 321-325, 2014.

STEWART, M. D. et al. BARD1 is necessary for ubiquitylation of nucleosomal histone $\mathrm{H} 2 \mathrm{~A}$ and for transcriptional regulation of estrogen metabolism genes. Proceedings of the National Academy of Sciences, v. 115, n. 6, P. 1316 LP-1321, 6 fev. 2018

TANNOCK, I. F.; HICKMAN, J. A. Limits to Personalized Cancer Medicine. New England Journal of Medicine, v. 362, n. 5, p. 567-571, 2016.

U.S. FOOD AND DRUG ADMINISTRATION. Paving the Way for Personalized Medicine Paving the Way for Personalized Medicine. FDA's Role in a New Era of Medical Product Development, n. October, p. 1-62, 2013.

WU, Y.; SARKISSYAN, M.; VADGAMA, J. V. Epigenetics in breast and prostate cancer. Methods in molecular biology (Clifton, N.J.), v. 1238, p. 425-466, 2015. 